\title{
Food for thought ... it's now time to talk
}

Sex - its pleasures and outcomes have always been a hot topic for discussion. Sexual health - the promotion of positive sexual wellbeing - is seldom addressed in the same up-beat way. To address this, the findings of the recently published National Survey of Sexual Attitudes and Lifestyles (NATSAL) ${ }^{1-3}$ and the publication of the National Strategy for Sexual Health and $\mathrm{HIV}^{4}$ for England provides direction for how sexual health services should be delivered in the future.

NATSAL findings about sexual behaviours and attitudes illustrate trends that have wide practical implications. People are having more sexual partners, they are using contraception and condoms more, but not consistently, sexually transmitted infections (STIs) are increasing, particularly Chlamydia. Importantly what this research shows is that there is a wide variability in sexual lifestyles by age, gender, relationships and residence and this is normal. These findings are valuable, not least because they confirm what many professionals working at grass roots level already know, i.e. what people feel, think, do and importantly do not do. Research continues to confirm that people do not always behave rationally, or in an organised or planned manner with their sex lives. The personal and public health consequences of unplanned pregnancy and STIs, coupled with issues that relate to education, employment, deprivation and inequalities, illustrate graphically why sexual health services have to change. There is a need for services to develop a holistic approach and become more 'person-centred' to address more than 'just the waist down' but involve hearts and minds too. Rethinking services for the future will involve creativity and new approaches. It will take time, energy and resources and will require honest, open and improved dialogue which will demand that all professionals working in sexual health really talk together and talk with users, potential users and non-users of services.

The Sexual Health Strategy provides the framework for this process of change, but it does not yet fill in the information. Filling in the gaps requires the NATSAL research questions to be answered, namely:

- How can services be developed to appropriately support people with varying sexual lifestyles and choices in a way that stops 'labelling'?
- What is an adequate framework of information and service provision, which will meet increasing demand and expectation?

- How do we close the gap between 'knowing about contraception and safer sex' and using contraception and protection consistently and well?

- What are the barriers that prevent clinical and nonclinical professionals properly talking with each other?

- Why isn't there a recognition of need for sexual health training?

To implement a Sexual Health Strategy that has longlasting benefit we need to address these questions. To achieve positive outcomes robust, workable frameworks are needed that should include:

- Creating environments at political level that are supportive of sexual health.

- Providing an integrated, multi-provider approach to sexual health services and resources across communities - partnerships that bring together care, treatment and health promotion.

- Developing personal and social skills through training, research, education and information.

- Involving local communities in setting priorities and implementing them.

Turning ideas, principles and thoughtful policies into practice will take commitment. We will not always get this right, but it's a responsibility we can all share as long as we keep talking about it and move on.

Statements on funding and competing interests

Funding. None declared.

Competing interests. None declared.

Toni Belfield, BSc, FRSH

Director of Information, fpa, 2-12 Pentonville Road, London N1 9FP, UK. E-mail: tonib@fpa.org.uk

References

Johnson et al. Sexual behaviour in Britain: partnerships, practices, and HIV risk behaviours. Lancet 2001 ; 358: 1835-1842.

Wellings et al. Sexual behaviour in Britain: early heterosexual experience. Lancet 2001; 358 : 1843-1850.

Fenton et al. Sexual behaviour in Britain: reported sexually transmitted infections and prevalen genital Chlamydia trachomatis infection. Lancet 2001; 358: 1851-1854

Department of Health. The National Strategy for Sexual Health and HIV, 2001

Editor's Note. For reviews of the three NATSAL papers published in the Lancet in December 2001 see Journal Club on page $107-108$. 